\title{
AC 2009-504: INTRODUCING BIONANOTECHNOLOGY INTO UNDERGRADUATE BIOMEDICAL ENGINEERING
}

\section{Aura Gimm, Duke University}

J. Aura Gimm is Assistant Professor of the Practice and Associated Director of Undergraduate Studies in the Department of Biomedical Engineering at Duke University. She teaches courses in biomaterials, thermodynamics/kinetics, engineering design, and a new course in

bionanotechnology. Dr. Gimm received her S.B. in Chemical Engineering and Biology from MIT, and her Ph.D. in Bioengineering from UC-Berkeley. 


\title{
Introducing Bionanotechnology in Undergraduate Biomedical Engineering
}

\begin{abstract}
As a part of the NSF-funded Nanotechnology Undergraduate Education Program, we have developed and implemented a new upper division elective course in Biomedical Engineering titled "Introduction to Bionanotechnology Engineering". The pilot course included five handson "Nanolab" modules that guided students through specific aspects of nanomaterials and engineering design in addition to lecture topics such as scaling effects, quantum effects, electrical/optical properties at nanoscale, self-assembly, nanostructures, nanofabrication, biomotors, biological designing, biosensors, etc. Students also interacted with researchers currently working in the areas of nanomedicine, self-assembly, tribiology, and nanobiomaterials to learn first-hand the engineering and design challenges. The course culminated with research or design proposals and oral presentations that addressed specific engineering/design issues facing nanobiotechnology and/or nanomedicine. The assessment also included an exam (only first offering), laboratory write-ups, reading of research journal articles and analysis, and an essay on ethical/societal implications of nanotechnology, and summative questionnaire. The course exposed students to cross-disciplinary intersections that occur between biomedical engineering, materials science, chemistry, physics, and biology when working at the nanoscale. We will also discuss the lessons learned and changes made between the first and the second time the course was offered.
\end{abstract}

\section{Introduction}

Nanoscience offers fresh perspectives on and unexpected solutions to a wide range of unsolved problems in semiconductors, optics, sensing, and biotechnology. Nanomaterials promise everything from faster and smaller electronics to more effective and precisely targeted therapies. Much of the current excitement about nanomaterials involves biomedicine due to the fact that nanoscale materials are the appropriate size to interact with important biological actors, such as proteins, DNA molecules, and viruses. For example, delivery strategies that employ polymeric nanoparticles are currently being developed and used in the fight against diseases such as malaria. The nanoparticles, which carry specific stimulating molecules and addressing molecules, are taken up by targeted immune cells, triggering an increased and more specific immune response ${ }^{1}$. Although nanoscience promises major benefits for health and may make possible a wealth of new technologies, there have also been concerns about possible harmful effects of nanomaterials on health ${ }^{2-3}$.

The emerging field of nanoscale science and engineering provides tremendous potential to allow scientists and engineers to improve existing products or to enable completely new applications. In order to realize this potential, the workforce needs to be trained and educated in the interdisciplinary fields that provide the intellectual foundation for nanotechnology ${ }^{4}$. For this reason, there is a large effort underway to incorporate interdisciplinary training and nanoscale science and technology education into existing undergraduate and graduate, and precollege curricula ${ }^{5}$. 
The new upper division course in "introduction to bionanotechnology engineering" was developed and offered in BME that meets the ongoing interests of our undergraduate and graduate students. The lecture modules focused on emergence of nano and biotechnologies, properties of nanomaterials, nanoscale characterization, and applications. The course emphasizes basic principles of engineering design while examining larger more complex biological systems. A number of laboratory modules ("NanoLabs") implemented to guide students through specific aspects of nanotechnology and existing tools. In a final project, students worked in teams to address specific design issues surrounding a number of areas including nanomedicine and biosensors. The course was offered twice with limited enrollments in fall 2007 (12 students) and 2008 (11 students). A number of changes were made in response to student comments after the first offering and this paper will discuss the course structure during the second offering.

\section{Course Structure}

The course combined lectures, student-led presentations on journal articles, "Nanolab" modules and their write-ups or reports, and a major team project that lead to final presentations and reports. The course schedule is shown in Table 1. Lecture topics included scaling effects, quantum effects, electrical/optical properties at nanoscale, self-assembly, nanostructures, nanofabrication, biomotors, biological designing, biosensors, nanomedicine. As a biomedical engineering elective, the course focused more on what biotechnology can bring to nanotechnology applications and their combined challenges. The course also included a number of guest lectures by bionanotechnology researchers on campus.

\section{Course objectives included:}

- To enhance appreciation of the current state and potential future impact of nanotechnology.

- To demonstrate how specific physical behavior and engineering design requirements change with scale

- To enhance understanding of emerging research in nanotechnology and nanomedicine and how these systems can be modulated using systems engineering and design principles.

- To expose students to cross-disciplinary intersections those occur between biomedical engineering, materials science, chemistry, physics, and biology when working at the nanoscale.

Assessment of student performance included their Table 1. Course syllabus

\begin{tabular}{|c|c|}
\hline Week & Topics \\
\hline 1 & $\begin{array}{l}\text { Introduction } \\
\text { Scaling effect }\end{array}$ \\
\hline 2 & $\begin{array}{l}\text { Quantum mechanics- electrical, } \\
\text { optical, magnetic properties }\end{array}$ \\
\hline 3 & $\begin{array}{l}\text { Nanolab: Au colloids } \\
\text { Nanostructures (1) }\end{array}$ \\
\hline 4 & $\begin{array}{l}\text { Nanofabrication: top-down } \\
\text { Vs. bottom-up (2) }\end{array}$ \\
\hline 5 & $\begin{array}{l}\text { Nanolab: Soft-lithography } \\
\text { Self-assembly and templating } \\
\text { "Seeing" nanostructures (3) }\end{array}$ \\
\hline 6 & $\begin{array}{l}\text { Nanolab: CdSe quantum dots } \\
\text { Biological design and Biomotors (4) }\end{array}$ \\
\hline 7 & Bio-inspired nanostructures (5) \\
\hline 8 & $\begin{array}{l}\text { Nanostructures in medicine } \\
\text { Nanomedicine }(6)\end{array}$ \\
\hline 9 & $\begin{array}{l}\text { Nanolab: Magnetite synthesis } \\
\text { Biosensor applications ( } 7 \text { ) }\end{array}$ \\
\hline 10 & $\begin{array}{l}\text { Nanolab: AFM module } \\
\text { DNA templating and quantum } \\
\text { computing }\end{array}$ \\
\hline 11 & $\begin{array}{l}\text { Nanolab: Ni nanowires } \\
\text { Molecular electronics (8) }\end{array}$ \\
\hline 12 & Nanolab: SEM module \\
\hline 13 & $\begin{array}{l}\text { Ethical/societal implications of } \\
\text { nanobiotechnology (9) }\end{array}$ \\
\hline 14 & Presentations and feedback \\
\hline
\end{tabular}
laboratory work, final team presentation and report, and individual presentations on journal articles and homeworks on reading materials which were 
mostly primary journal articles. The readings also included a number of reviews and articles from popular science magazines. Two example readings/write-ups are shown in Table 2.

Table 2. Samples of readings/write-up questions used in the course
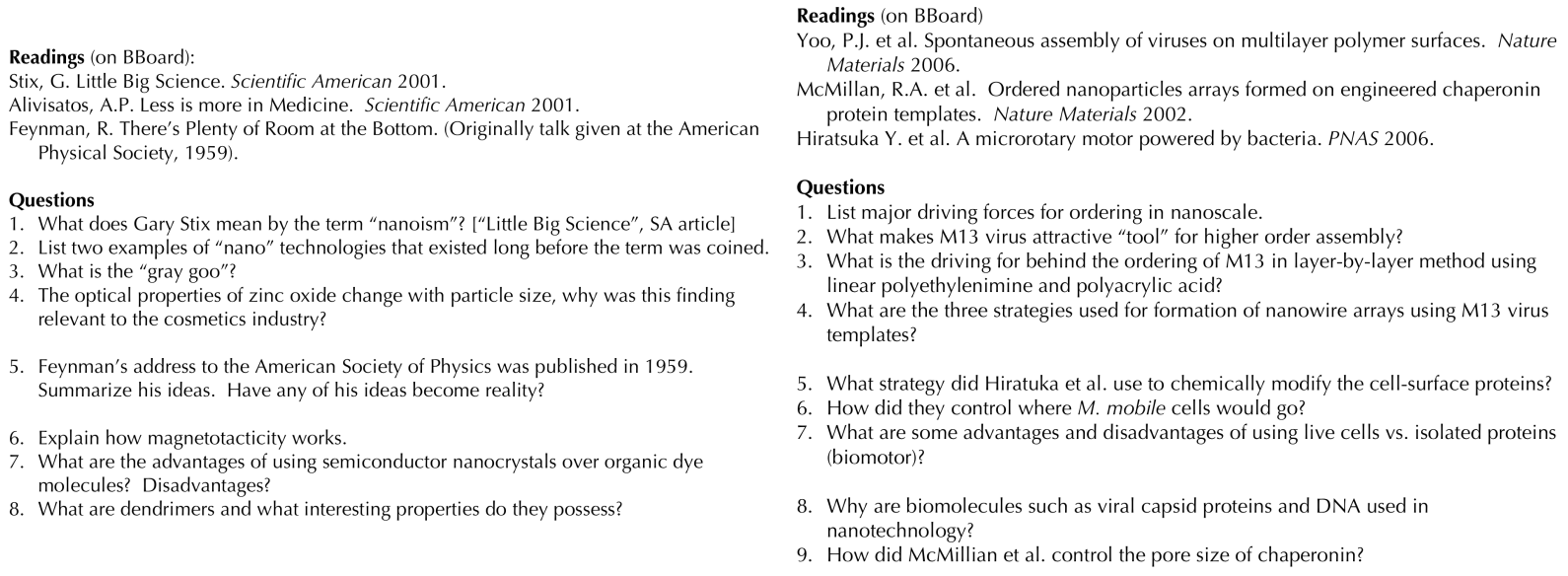

\section{NanoLab Modules}

A handful of nanotechnology-based laboratory modules were adopted from existing sources ${ }^{6}$ with changes and additions to match student experience. In addition to performing the lab, the students completed write-ups that involved reading additional journal articles that are related to each lab. During the second year, a full laboratory report (on the AFM module) was added.

There are five stand alone laboratories including gold colloid synthesis, softlithography: SAM $\mu$-contact printing, CdSe quantum dot synthesis, magnetite (ferrofluid) synthesis and nickel nanowire synthesis (Figure 1).

Soft-lithography lab module demonstrates the structure and activities of a typical "NanoLab".
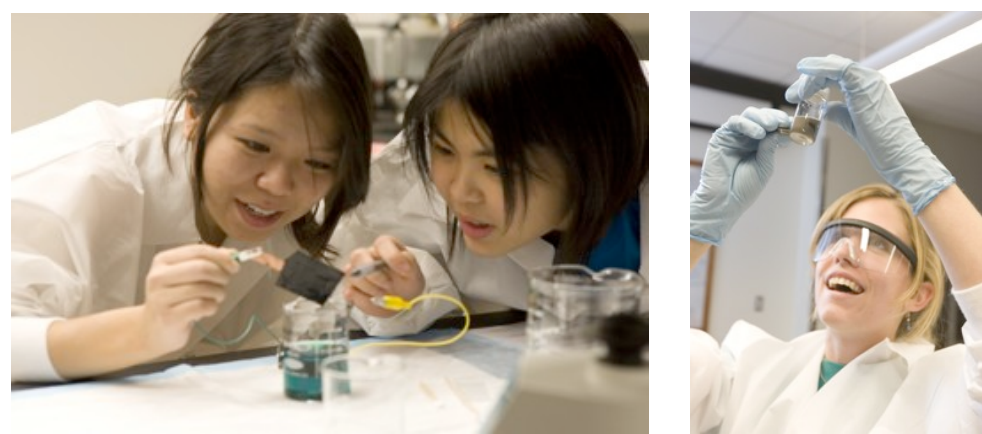

Figure 1. Students synthesizing nickel nanowires using templatebased electrodeposition; uses of magnets can control movement of these nanowires since nickel is magnetic.

In this lab students build on the lectures on self-assembled monolayers by creating alkanethiol SAMs on silver coated glass using PDMS (polydimethylsiloxane, rubbery polymer) stamp of coins. The laboratory guide includes relevant background information and procedures for 1) silver coating of glass slides, 2) making of fine-featured rubber stamp using PDMS, 3) inking and transferring of SAM using the stamp (procedure commonly known as $\mu$-contact printing), and 4) testing of surface effect seen by breathing on the stamped area. The supplementary readings and the post-lab write-up questions are shown in Table 3. 
During the second year of the course, two major instrumentation modules were added. A relatively inexpensive atomic force microscope that was dedicated to educational use was purchased. As first implementation of the AFM module, students examined the roughness of all the samples they themselves synthesized earlier in the course. In addition, we were able to utilize the SEM/TEM of the Shared Materials Facilities on campus that had recently opened its doors to educational uses. Students were given tours of the cleanroom facilities followed by sessions on SEM and TEM examining gold colloids, quantum dots, and nickel nanowires they have made.

\section{Team Projects}

The main goal of the team project was to expose students to the large number of design and engineering challenges found in application of bionanotechnology. These challenges were multidisciplinary by nature. Students were required to understand specific biological issues when relevant for their projects, such as learning about specific cancer biology or different modes of drug delivery. During the first

Table 3. Readings and questions for soft-lithography and $\mu$-contact printing lab

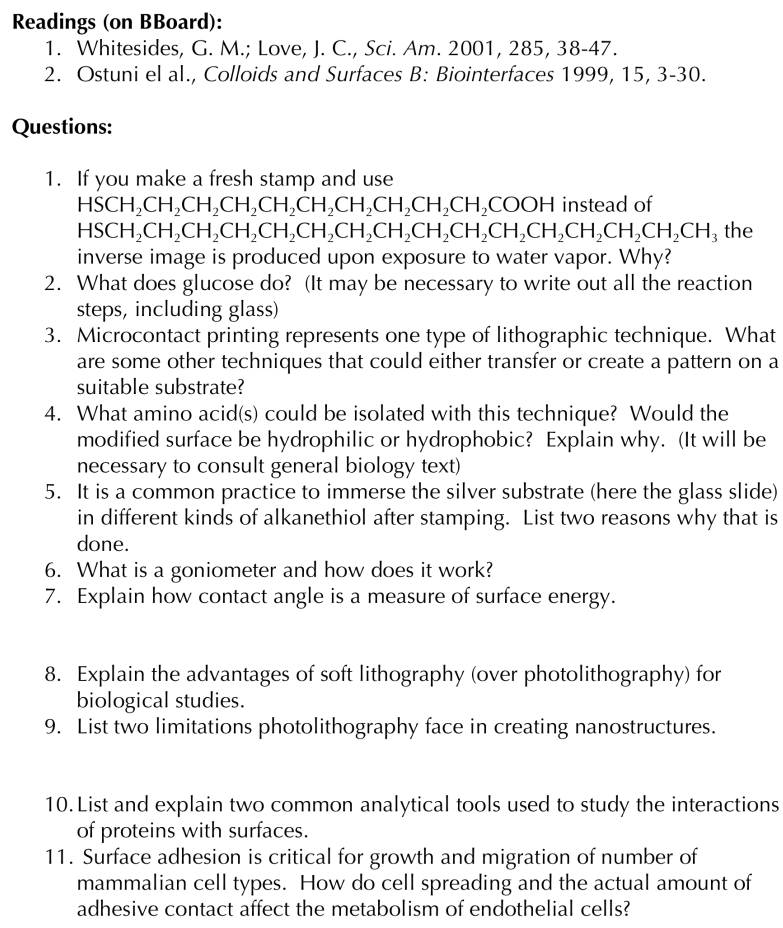

4. What amino acid(s) could be isolated with this technique? Would the modified surface be hydrophilic or hydrophobic? Explain why. (It will be necessary to consult general biology text)

5. It is a common practice to immerse the silver substrate (here the glass slide) in different kinds of alkanethiol after stamping. List two reasons why that is done.

6. What is a goniometer and how does it work?

7. Explain how contact angle is a measure of surface energy.

8. Explain the advantages of soft lithography (over photolithography) for biological studies.

9. List two limitations photolithography face in creating nanostructures.

10. List and explain two common analytical tools used to study the interactions of proteins with surfaces.

11. Surface adhesion is critical for growth and migration of number of mammalian cell types. How do cell spreading and the actual amount of adhesive contact affect the metabolism of endothelial cells? offering of the course, the students were asked to report their findings in the form of a grant proposal that included proposed experiments and testing. Topics from the first year included:

- Nanopore-based diagnostics (Figure 2)

- Use of quantum dots for photodynamic therapy of breast cancer (Figure 3)

- CNT-based supercapacitor driven biologically responsible pacemaker.

- Minimization of cytotoxicity of carbon nanotube in drug delivery (Figure 4).

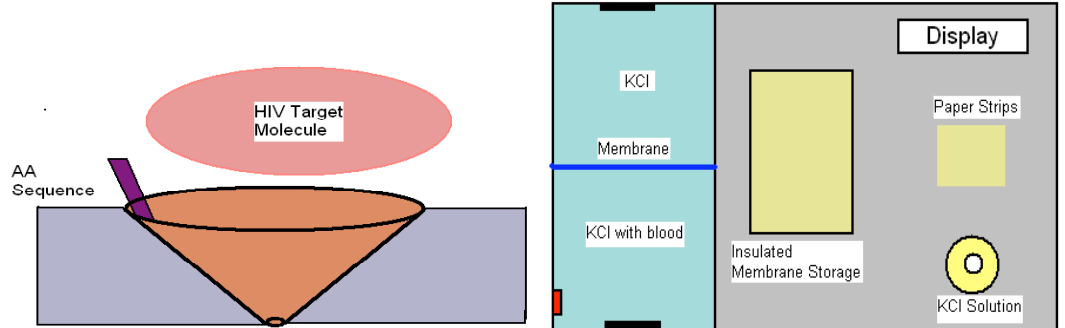

Figure 2. Conceptual design for nanopore- membrane diagnostics for HIV

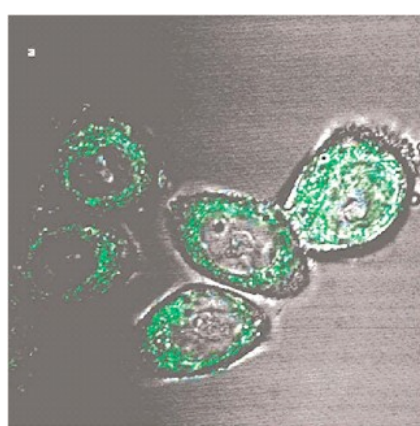

Figure 3. Image of uptake of quantum dots by SK-BR-3 cancer cell line. Idea behind using quantum dots for photodynamic therapy (Image is from ref. 7) 
The project goals and deliverables shifted for the second year of the course. The students were asked to 1) think about the nanoparticles that can be used in medicine or biological applications, 2) think about possible applications (such as improving targeting of drugs to lungs) and how nanotechnology or nanomedicine can improve existing approaches, or 3) think about biological motors as possible building blocks for novel technology (energy, sensing and detection or diagnosis). Once the teams and topics were chosen, teams were asked address the main engineering design (used broadly) challenges that must be solved to achieving the future promise of that specific nanotechnology application. For example, the idea of using motor proteins to control cargo manipulation on a lab-on-a-chip to sort, separate, purify, or assemble other materials - we can address where we are with

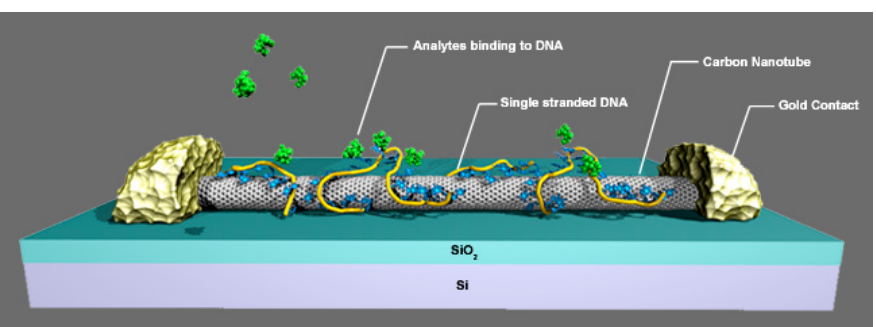

Figure 4. DNA-Functionalized Carbon Nanotube Chemical Sensor. Idea behind using surface modifications (covalent and non-covalent) to mitigate cytotoxicity seen with carbon nanotubes. (Image is from ref. 8) current technology, what design challenges need to be solved, and what are some of strategies for solving them. The topics for the team projects during this term included:

- Design challenges of nanomedicine using drug vehicles

- Nanotechnology applications in developing world

- Design challenges of using biomotors in nanomedicine (Figure 5).

Students were typically divided into teams of 2-3 students and were asked to submit and have their project proposal approved before moving onto in-depth research. Once the project ideas were approved, a number of team meetings were held to advise and guide each project. The expectations for the final report and presentations varied depending on the project topic, degree of challenge, and the availability of resources.

Students also participated in peer-assessment of the final presentation and the grade reflected the audience assessment in addition to that of the instructor. Table 4 shows the form used for peer-assessing student presentations.
Table 4. Peer-assessment form for final presentations

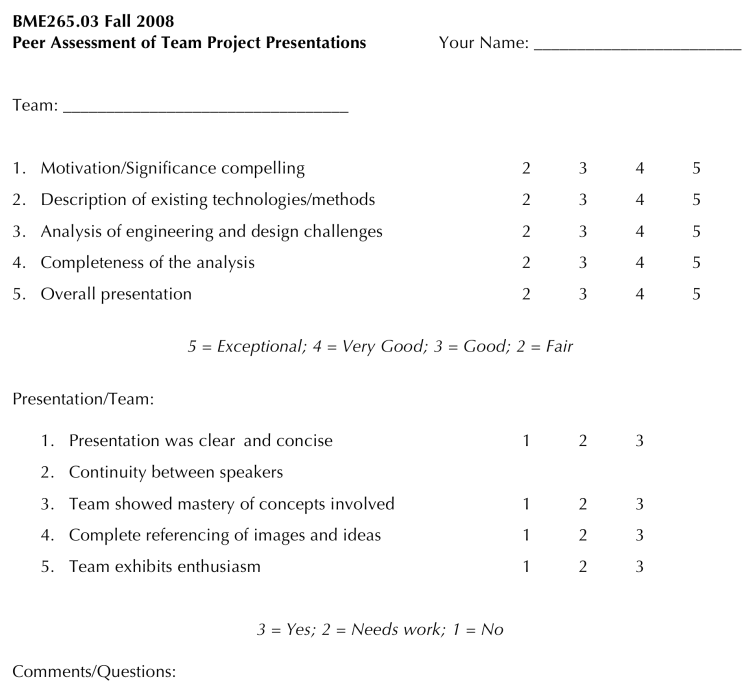




\section{Student Population and Feedback}

The course was an elective BME course. Our curriculum requires four BME electives for the completion of the degree. Most electives are considered to be upper division courses taken by mostly seniors and some juniors. The 200-level electives are also taken by graduate students in the program. The course was one-credit hour for undergraduates (all undergraduate courses are counted the same in our institution), and threecredit hours for graduate students. Table 5 shows the distribution of student population who took the course. Course enrollment was capped at 12 . The prerequisites were introductory biomaterials (BME83L) and another core BME course that combines thermodynamics and kinetics (BME100L, Modeling Cellular and Molecular Systems), or permission of the instructor. There were some variability in fulfillment of prerequisites among graduate students as expected, however, all had to obtain a permission number from the instructor.

A self-reported exit survey was used to obtain student feed back on the course. The survey (first page of survey shown in Table 5) included ratings of knowledge in specific topical areas before and after taking the course (Figure 6). It also included a number written questions that ask what important concepts students learned, what concepts they thought were lacking, their feedback on NanoLab modules and whether the lab modules increased student appreciation of multidisciplinarity of bionanotechnology, and whether the course has affected student view of scientific research.

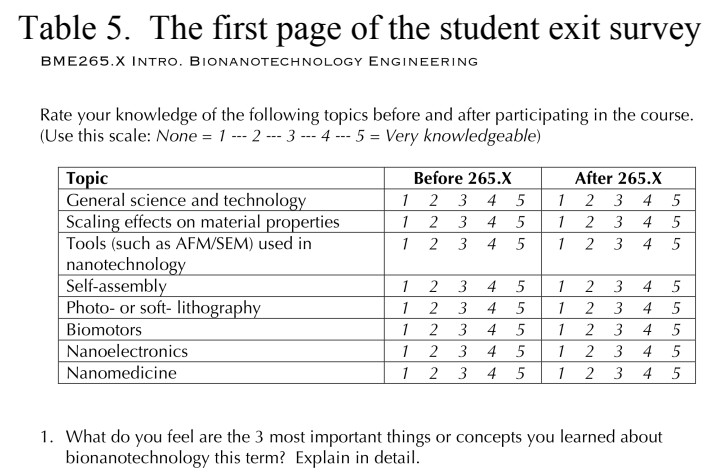

2. Were there any specific topics that you feel should be included in the course?
Table 5. Student distribution

(all BME)

Masters students (BME, ME

Eng. Management)

Ph. D. students (all BME)

$\begin{array}{cc}\text { Fall } 2007 & \text { Fall } 2008 \\ 5 & 3 \\ 2 & 6 \\ 4 & 2\end{array}$

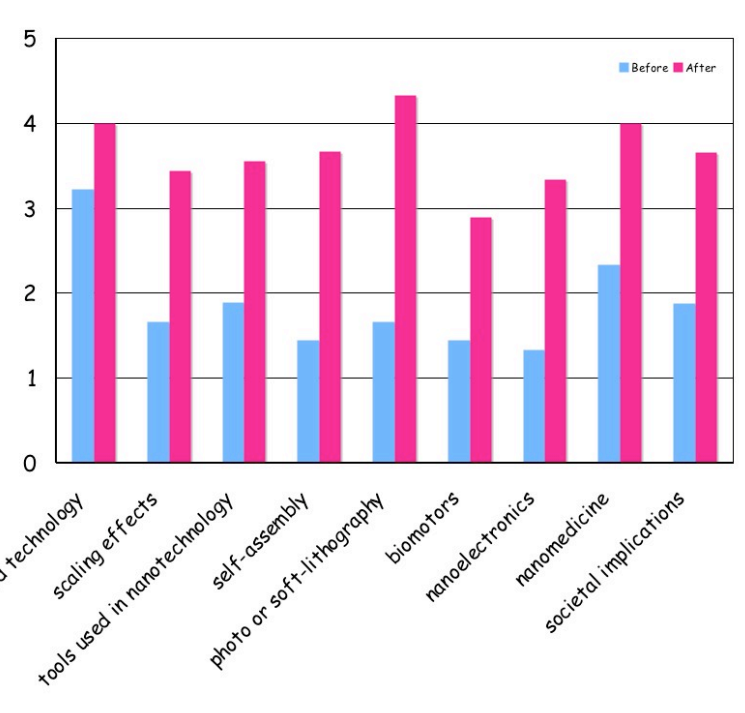

Figure 6. Results from "Rate your knowledge in the following topic areas before/after participating in the course" (None $=1$----> $5=$ very knowledgeable), from fall $2007, \mathrm{n}=9$ for this survey, only averages are used.

There was unanimous consensus amongst students on the importance of NanoLab modules as learning tools. Students appreciated both the hands-on experience and the simplicity (not requiring "fancy equipment"). There were mixed (as expected) responses to all other questions 
on the exit survey. For an example, for the "3 most important things or concepts you learned", the most frequent responses included self-assembly, scaling effects, biomotors, and nanomedicine.

\section{Changes between $1^{\text {st }}$ and $2^{\text {nd }}$ offering of the course}

Some of the changes made between the first and second offerings of the course that were related to the team projects and NanoLab modules were discussed above. In addition, there were major structural changes for assessing student performances. One in-class exam was used to assess student learning of nanoscale concepts during the first offering of the course. The exam paralleled the textbook we used that term. The textbook and the exam were abandoned for the second offering in Fall 2008 for a number reasons including the lack of appropriate textbook for the course and better alignment of course objectives with the skills that our students need to pursue further studies in nanoscience or biomedical engineering as whole. We focused more on development of skills necessary to read/approach primary journal articles and individual presentation skills. Each student had to lead a discussion on a specific journal articles for the class. These include explaining the motivation, all the figures, addressing the significance of the findings of each paper, and background research of specific materials/methods employed. All the activities including the individual presentations were graded and feedbacks given. Direct use of primary journal articles allowed for both the expanded view of the bionanotechnology area of research and the depth seen in each specific area. It also allowed the course to follow the cutting edge research as they happen.

\section{Conclusion}

An upper division elective course in bionanotechnology was developed and implemented for two semesters. The course integrated a number of lectures on specific nanoscale and biotechnology concepts, included fairly inexpensive "NanoLab" modules that required limited resources with additional reading and homework material. The students also worked in teams to address some of engineering and/or design challenges facing bionanotechnology in the areas of nanomedicine, diagnostics, and other areas of their interest. The course with its flexible structure can be easily adopted by other biomedical or bioengineering programs.

\section{Acknowledgements}

We are grateful to the National Science Foundation though the Nanotechnology Undergraduate Education Award (award \# EEC-0634230) for the support.

\section{References}

1. Irvine DJ, Stachowiak A, Jain S. "Engineering biomaterials for control of immune cell functions" Material Science Forum 426-4: 3213-3218 2003. 
2. Borm PJA, Kreyling W. "Toxicological hazards of inhaled nanoparticles - Potential implications for drug delivery" Journal of Nanoscience and Nanotechnology 4 (5): 521-531 2004.

3. Dreher KL. "Health and environmental impact of nanotechnology: Toxicological assessment of manufactured nanoparticles" Toxicological Sciences 77 (1): 3-5 2004.

4. Roco, MC. "Converging Science and Technology at the Nanoscale: Opportunities for Education and Training" Nature Biotechnology, 21 1247-1249 2003.

5. Nanotechnology Research and Development Act of 2003 (Referred to Senate Committee after being Received from House), H.R.766.RFS. http://thomas.loc.gov/ (accessed April 2005).

6. Interdisciplinary Education Group, University of Wisconsin Materials Research Science and Engineering Center (MRSEC) on Nanostructured Materials and Interfaces. http://mrsec.wisc.edu/Edetc/nanolab/index.html (accessed January 2009)

7. Zhu MQ et al. "Surface modification and functionalization of semiconductor quantum dots through reactive coating of silanes in toluene" Journal of Materials Chemistry 17: 800-805 2007.

8. Charlie Johnson Group: Experimental Nanoscale Physics.

http://www.lrsm.upenn.edu/ nanophys/biosensors.html (accessed January 2009). 